\title{
Investigations of driver's speed at unsignalised pedestrian crossings
}

\author{
Robert Ziolkowski ${ }^{1}$ \\ ${ }^{1}$ Bialystok University of Poland, Faculty of Civil and Environmental Engineering, Wiejska 45E, 15-351 Bialystok, Poland
}

\begin{abstract}
Pedestrian crossings are critical places for road accidents involving pedestrians and motor vehicles. Due to the relation between speed and injury severe the driver's speed has a crucial impact on pedestrian safety. In Poland the traffic-related death rate of unprotected road users is extremely high comparing to other countries of European Union even though the traffic law regulations require from drivers special attention and slowing down while approaching to the intersection and/or zebra pedestrian crossing area. The goal of the paper is to investigate driver's speed while approaching to the pedestrian crossings located in mid-block areas and in inlet sections of unsignalised intersections and roundabouts. For this purpose the spot speed measurements in free flow traffic conditions were conducted using radar speed gun. Speed was recorded at a distance of $100 \mathrm{~m}$ and $50 \mathrm{~m}$ from the crossing as well as at the zebra crossing location. As a result driver's speed behaviour based on statistical analysis and depending on the type, localization and distance from the pedestrian crossing was analysed and evaluated.
\end{abstract}

\section{Introduction}

Pedestrians are highly threatened group of road users. Being deprived of effective protection during a collision with a vehicle they experience serious injuries or become victims as a result of high hit energy emerging from high speed driving. In Poland the safety indicators related to pedestrian death and injuries remain the highest within EU countries. A high percentage of pedestrian-vehicle accidents occur in the area of pedestrian crossings, places that theoretically should to provide especially high level of pedestrian's safety [1]. In recent years the number of victims registered on pedestrian crossings in Poland has accounted to $30 \%$ of all victims but the problem is actual in a world-wide scale [2, 3, 4]. The graph reflecting pedestrians fatality in European Union countries is showed in Figure 1 [5].

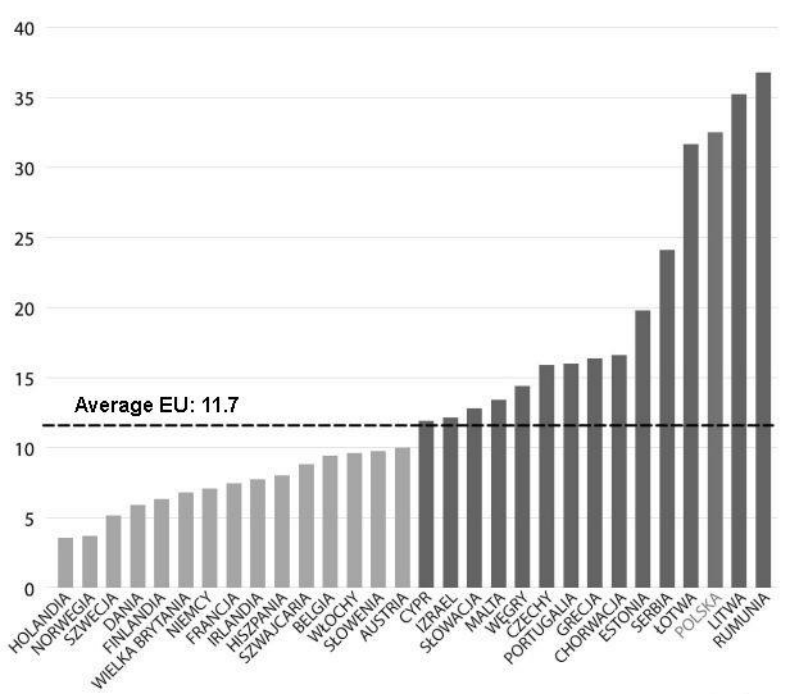

Fig. 1. Pedestrian fatalities in EU, per million inhabitants [5]
Main directions of traffic safety analyses remain within three dominant safety factors: human-vehicleroad and its environment. Pedestrian behaviour analyses bring the core information for transportation and design practices as well as safety risk analyses [6]. A number of studies examined the pedestrian characteristics on sidewalks or pedestrian flow characteristics at signalised intersections to develop pedestrian models for evaluation of walking facilities [7, 8]. Another studies related to human's factor have included pedestrian accidents characteristics in Europe $[9,10,11]$ pointing restricted visibility, poor infrastructure, forcing the right of way, driver's attitude and reckless driving as the grounds of accidents. Similar conclusions arise from Polish research works [12, 13]. Some investigations based on driver's speed and image analyses were also conducted to determine pedestrian's behaviour and driver-pedestrian interaction in terms of driver's speed depending on the pedestrian presence $[14,15]$. Many works also underline and include speed characteristics in statistical models describing pedestrian fatality risk [16, 17]. Road geometry and its infrastructure are rather consider in terms of average speeds in mid-block segments and traffic conditions [18, 19]. According to a study conducted by the U.K. Department of Transportation [20] the probability of pedestrian death is $85 \%$ when the striking vehicle is travelling at $60 \mathrm{~km} / \mathrm{h}$. this probability drops to about $45 \%$ for $45 \mathrm{~km} / \mathrm{h}$ impact and drops further to $5 \%$ if the vehicle is travelling at $30 \mathrm{~km} / \mathrm{h}$ at impact. This clearly show how important is to know driver's speed at the possible collision point with a pedestrian and to keep this speed at low level.

The main objective of this study was to evaluate driver's speed behaviour at different types of pedestrian crossings and different distances from them. Observation

\footnotetext{
* Corresponding author: author@e-mail.org
} 
sites were selected to obtain varied road geometry conditions considering a type of a cross section.

\section{Site survey and speed acquisition}

Research area included 19 unsignalised pedestrian crossings with refugee islands situated in Bialystok, in areas of low to medium density development with speed limit $50 \mathrm{~km} / \mathrm{h}$. The crossings were located in mid-blocks areas ( 7 crossings), in inlet sections of unsignalised intersections ( 7 crossings) and in inlet sections of roundabouts ( 5 crossings). The investigations excluded crossings with traffic lights. The speed surveys were conducted in three checkpoints: V_100, V_50 and V_0. The first one was located in the distance of about 100$140 \mathrm{~m}$ from the pedestrian crossing (preliminary speed measurements allowed to establish that driver's speed remains stable for mid-block segments), the second checkpoint was located at the distance of $50 \mathrm{~m}$ from the crossing and at the third one was situated at the stop line before the crossing. Speed surveys included 80-140 passenger cars in free-flow driving conditions. The speed data were gathered with the use of speed gun and the accuracy of the equipment was $+/-3 \mathrm{~km} / \mathrm{h}$ for speeds below $100 \mathrm{~km} / \mathrm{h}$. To minimize the effect of a surveyor with the radar gun on drivers' speed choice surveyor set in a car which was parked by the roadside in a way not to disturb drivers by its presence. To exclude the possible influence of pedestrians on driver's behaviour, vehicle's speed was recorded only in situations when no pedestrians were present at or in the nearest area of the crossing. In case of crossings located at unsignalised intersections only through driving vehicles were investigated. The speed measurements were conducted in a daytime and after dark.

\section{Speed results and discussion}

Speed data for free-flowing vehicles are shown in Table 1. In Table 1, MB denotes crossings located in midblock street sections, US denotes crossings at intersections without traffic lights and $\mathrm{R}$ denotes crossings located at roundabout's inlet.

As shown in Table 1 (Appendix 1), differences occur in average speeds between analysed locations depending on the type of a crossing and the position of a vehicle from the crossing. The highest average speeds were recorded at the furthest checkpoints located at the distance where drivers are not influenced at any way by the presence of the pedestrian crossings.

Table 1. Speed characteristics of the investigated pedestrian crossings.

\begin{tabular}{|c|c|c|c|c|c|c|c|}
\hline $\begin{array}{l}\text { Pedest } \\
\text { rian } \\
\text { crossi } \\
\text { ng }\end{array}$ & $\begin{array}{l}\text { Type } \\
\text { of a } \\
\text { cross } \\
\text { secti } \\
\text { on }\end{array}$ & $\begin{array}{l}\mathrm{V}_{-} 1 \\
00 \\
{[\mathrm{~km} /} \\
\mathrm{h}]\end{array}$ & $\begin{array}{l}\mathrm{SD}_{-} \\
100\end{array}$ & $\begin{array}{l}\text { V_50 } \\
{[\mathrm{km} /} \\
\mathrm{h}]\end{array}$ & $\begin{array}{l}\mathrm{SD}_{-} \\
50\end{array}$ & $\begin{array}{l}\text { V_0 } \\
{[\mathrm{km} /} \\
\mathrm{h}]\end{array}$ & $\begin{array}{c}\text { SD } \\
-0\end{array}$ \\
\hline MB_1 & $1 \times 2$ & 48,8 & 9,8 & 48,5 & 9,2 & 48,3 & 9,3 \\
\hline MB_2 & $1 \mathrm{x} 2$ & 51,3 & 7,6 & 51,0 & 7,1 & 49,9 & 6,8 \\
\hline MB_3 & $1 \times 2$ & 48,0 & 7,9 & 48,2 & 8,3 & 47,8 & 8,3 \\
\hline
\end{tabular}

\begin{tabular}{|l|l|l|l|l|l|l|l|}
\hline MB_4 & $1 \times 2$ & 47,9 & 7,3 & 47,5 & 6,7 & 46,9 & 6,2 \\
MB_5 & $2 \times 2$ & 57,9 & 8,7 & 55,1 & 8,2 & 53,1 & 7,9 \\
MB_6 & $2 \times 2$ & 56,8 & 8,4 & 54,1 & 7,1 & 53,0 & 7,1 \\
MB_7 & $1 \times 2$ & 52,1 & 7,3 & 50,9 & 7,0 & 50,9 & 6,5 \\
\hline US_1 & $2 \times 2$ & 57,8 & 9,1 & 55,9 & 7,9 & 52,4 & 6,7 \\
US_2 & $1 \times 2$ & 52,5 & 7,5 & 54,0 & 6,1 & 52,1 & 6,8 \\
US_3 & $1 \times 2$ & 49,0 & 7,1 & 48,9 & 7,1 & 47,1 & 6,7 \\
US_4 & $1 \times 2$ & 52,0 & 8,5 & 51,1 & 7,7 & 50,0 & 7,0 \\
US_5 & $2 \times 2$ & 54,4 & 6,5 & 51,9 & 6,5 & 50,2 & 5,5 \\
US_6 & $1 \times 2$ & 53,2 & 7,4 & 51,8 & 6,9 & 49,6 & 5,9 \\
US_7 & $1 \times 2$ & 52,2 & 7,6 & 52,0 & 7,4 & 50,5 & 6,4 \\
\hline R_1 & $1 \times 2$ & 49,6 & 4,6 & 45,3 & 4,1 & 40,8 & 4,3 \\
R_2 & $1 \times 2$ & 51,3 & 6,1 & 45,7 & 6,0 & 41,4 & 6,3 \\
R_3 & $1 \times 2$ & 51,1 & 9,3 & 45,9 & 7,8 & 40,2 & 6,0 \\
R_4 & $2 \times 2$ & 54,5 & 6,0 & 49,1 & 5,5 & 43,4 & 5,2 \\
R_5 & $2 \times 2$ & 53,7 & 8,4 & 50,5 & 7,6 & 43,1 & 6,5 \\
\hline
\end{tabular}

At the furthest from the pedestrian crossing checkpoint in general a high percentage of drivers exceeded the speed limit even though average values don't seem to be too high and remains on a similar level comparing speeds in terms of the type of a crossing. The highest values were stated at mid-block locations for US crossings $(52,4 \mathrm{~km} / \mathrm{h})$ and were higher by only $1,9 \%$ than the lowest values recorded for $\mathrm{R}$ crossings $(51,4$ $\mathrm{km} / \mathrm{h}$ ). Analysing speed values at closer distances to investigated crossings to the investigated crossings the highest values were recorded for vehicles approaching MB crossings $(51,6 \mathrm{~km} / \mathrm{h}$ and $50,4 \mathrm{~km} / \mathrm{h}$ respectively at checkpoint located $50 \mathrm{~m}$ and $0 \mathrm{~m}$ from the crossing) and the lowest values were recorded along approaching sections to roundabouts $(48,4 \mathrm{~km} / \mathrm{h}$ and $43,7 \mathrm{~km} / \mathrm{h}$ respectively). The differences between average speeds of the analysed locations do not exceed $7 \%$ and $15 \%$ respectively and are statistically insignificant $(p=, 08624)$. This situation is reflected in Figure 2 presenting the scatterplots of average speeds at the locations.

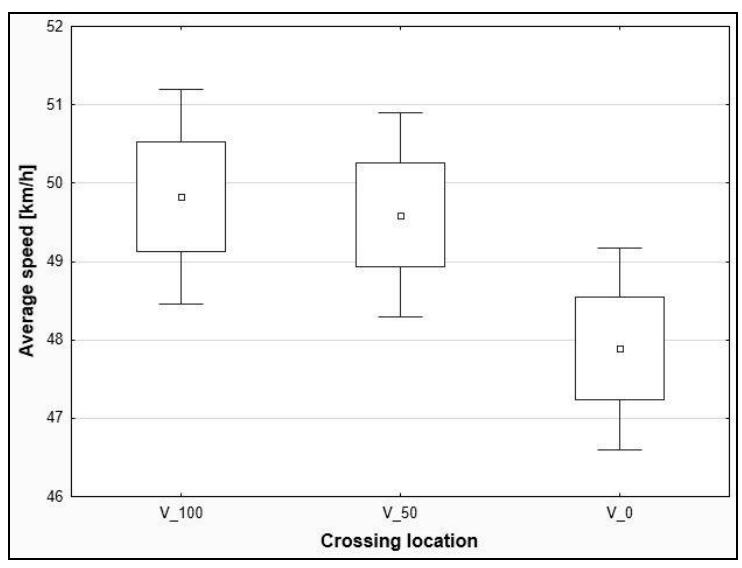

Fig. 2. Effect of pedestrian crossing location on average speed for MB crossings.

Data in Table 1 show different speed values in each group of pedestrian crossings. In the group of mid-block crossings the difference between highest and lowest V_100 value reaches $22 \%$. In case of V_50 and V_0 those differences are only little lower and equal to $18 \%$ and $19 \%$ respectively. In order to verify the significance of the differences the variance analysis was performed. As a result the high significance was confirmed for 
V_100 $(p=, 00213)$. However such a difference doesn't exist at a distance of $50 \mathrm{~m}$ nor $0 \mathrm{~m} \quad(\mathrm{p}=, 28838$ and $\mathrm{p}=, 34192$ respectively). The influence on individual's speed can be related to the cross section of a street so to verify that variance analysis was performed for regrouped $\mathrm{MB}$ crossings into single and dual carriageway groups. The analysis has confirmed that assumption on a high significance level $(\mathrm{p}=, 00000)$. However similar analyses conducted for separated groups V_50 and V_0 didn't reveal such differences. This can be explained by the fact that while coming to the pedestrian crossing driver's speeds become more inhomogenous regardless the type of a cross section.

Analogues analyses conducted for US crossings didn't show such a tendency. At every checkpoint the differences between average speeds were not significant and $p$ values varied between 0,23245 and 0,49951. Additional regrouping of the US crossings into single and dual carriageway didn't influence on the results.

In case of $\mathrm{R}$ crossings there was no significant differences between average speeds at each of the tested location (respectively $\mathrm{p}=, 34192 ; \mathrm{p}=, 56708 ; \mathrm{p}=, 58584$ ) but opposite to mid-block and unsignalised locations there was a significant difference between average speed V_100 and V_0 $(\mathrm{p}=, 00241)$ and also V_50 and V_0 $(p=, 02831)$. However that can be rather explained by the traffic organization and priority rules then the presence of the pedestrian crossing itself. Average speed values recorded at analysed crossings are presented in Figure 3.

a)

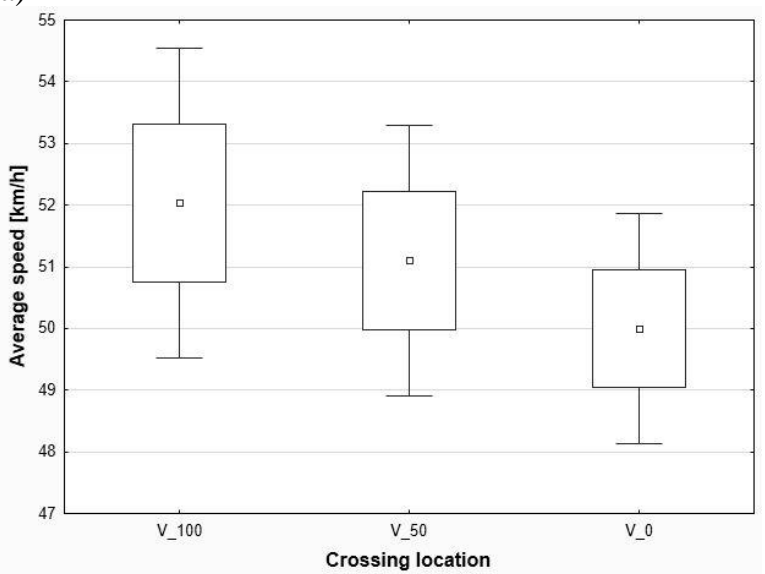

b)

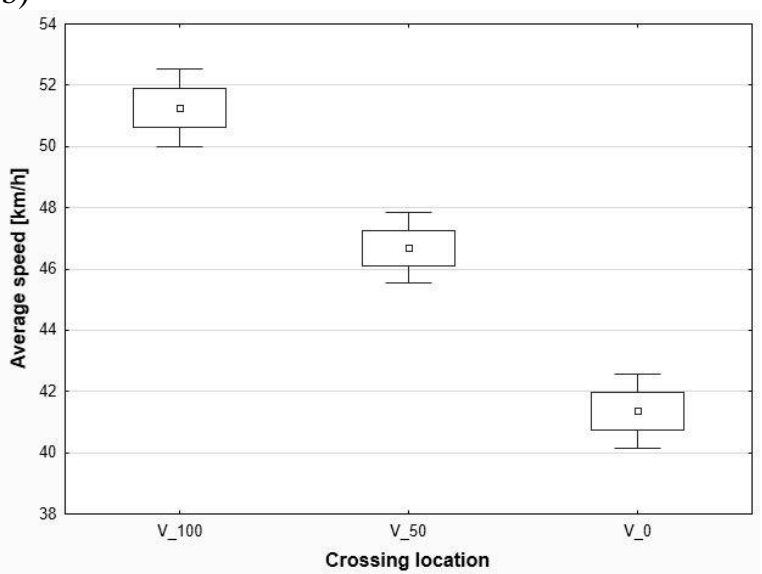

Fig. 3. Effect of pedestrian crossing location on average speeds for a) US crossings, b) R crossings.
In case of US crossing statistical analyses showed lack of significant differences between average values ( $p=, 44034$ ) opposite to $\mathrm{R}$ crossings where difference were highly significant $(\mathrm{p}=, 00000)$.

Figure 4 presents average speeds recorded for $\mathrm{MB}$ and US crossings in relation to the cross section of the street. a)

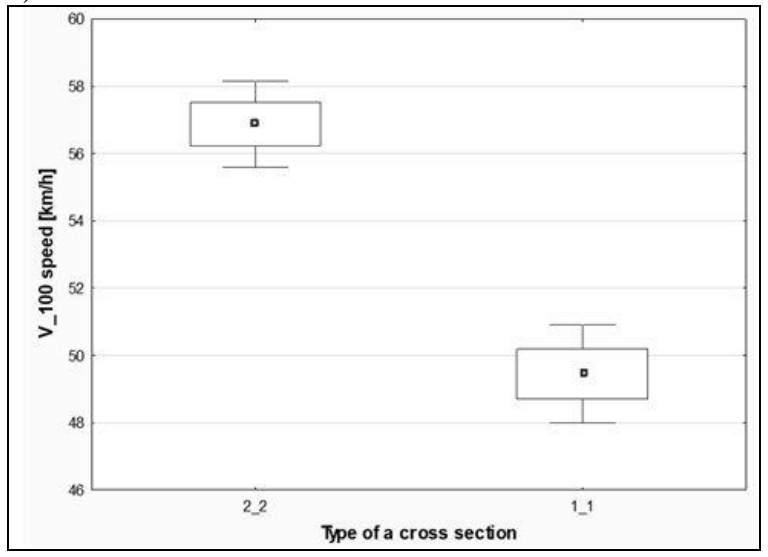

b)

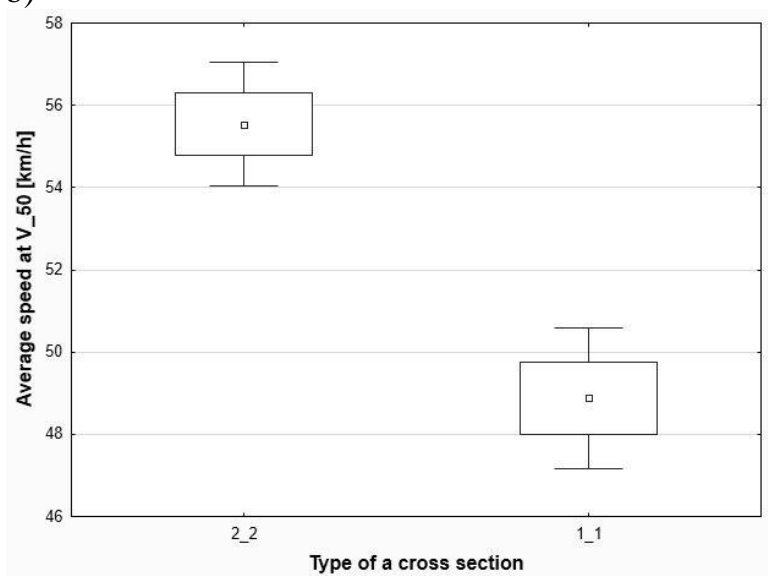

c)

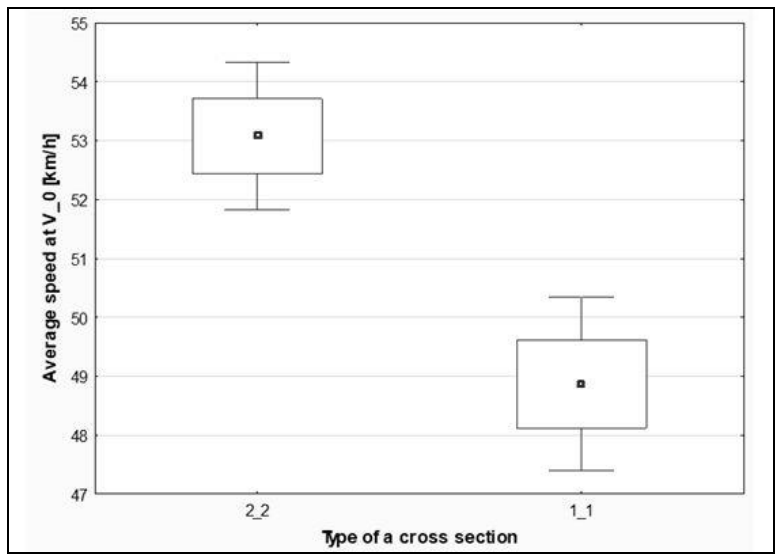

Fig. 4. Average speeds values depending on the type of a cross section a) V_100, b)V_50, c) V_0 for MB and US crossings.

As can be seen from the Figure 3, depending on the type of a cross section drivers travel with significantly different speeds within analysed segments for the existing speed limit $50 \mathrm{~km} / \mathrm{h}$ and the width of driving lanes at least $3,25 \mathrm{~m}$. It can be assumed that the total wider space provided by $2 \times 2$ cross section encourages 
drivers for faster driving. Average speeds recorded on dual carriageways are higher in comparison to average speeds on single carriageway by $14,7 \%$ (V_100), 13,9\% (V_50) and 8,6\% (V_0). In each case the significance level was very high with $\mathrm{p}=, 00000$ for $\mathrm{V}_{-} 100$ and $\mathrm{V} \_50$ and $\mathrm{p}=, 00002$ for V_0.

a)

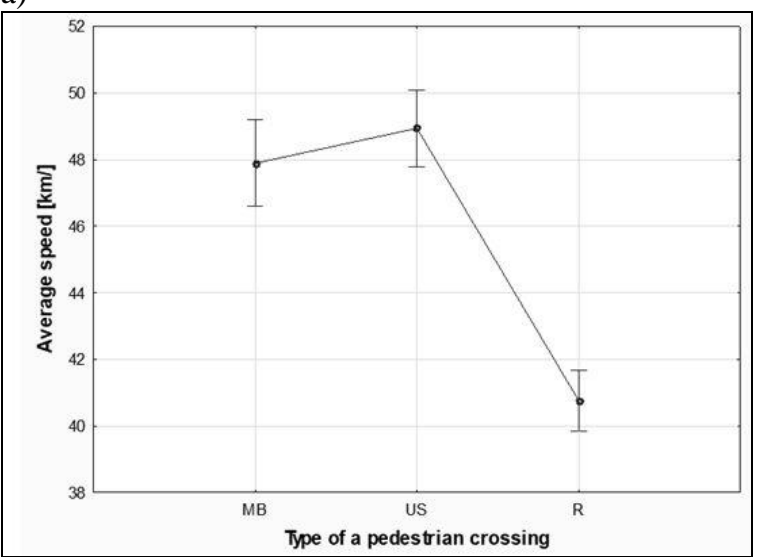

b)

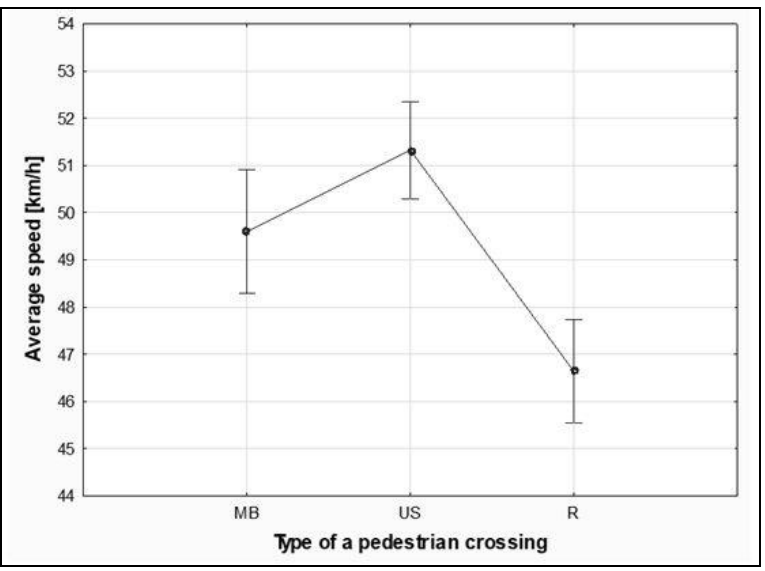

Fig. 5. Average speeds related to the localization of the pedestrian crossing recorded a) V_0 and b) V_50.

Figure 5 shows average speed values recorded at the pedestrian crossings (V_0) and at the distance of $50 \mathrm{~m}$ from the crossing in relation to their localization. For V_0 values the differences occurred to be significant $(p=, 00000)$ mainly because of distinctly lower speed value recorded in the approaching sections to roundabouts. Average $\mathrm{V}_{-} 0$ value for $\mathrm{R}$ was lower by $17,1 \%$ comparing to V_0 for $\mathrm{MB}$ crossings and by $19,6 \%$ comparing to US crossings. Similar tendency was observed at a distance of $50 \mathrm{~m}$ from the pedestrian crossings. The only difference lies in the size of the average speed values differences that amounted to $6,2 \%$ (comparing $\mathrm{MB}$ and $\mathrm{R}$ crossings) and 9,8\% (comparing US and R crossings). The differences in average $V_{-} 100$ values didn't exceed $4,6 \%$ and were insignificant $(p=, 086151)$. Comparisons of average speed between $\mathrm{MB}$ and US crossings didn't show significant differences.

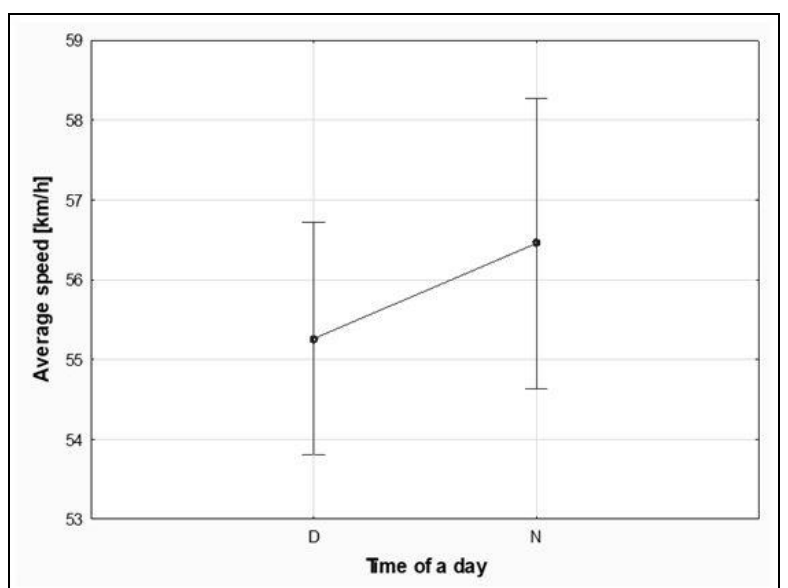

Fig. 6. Scatterplot of average $V_{-} 0$ speeds related to the time of a day for $2 \times 2$ cross sections.

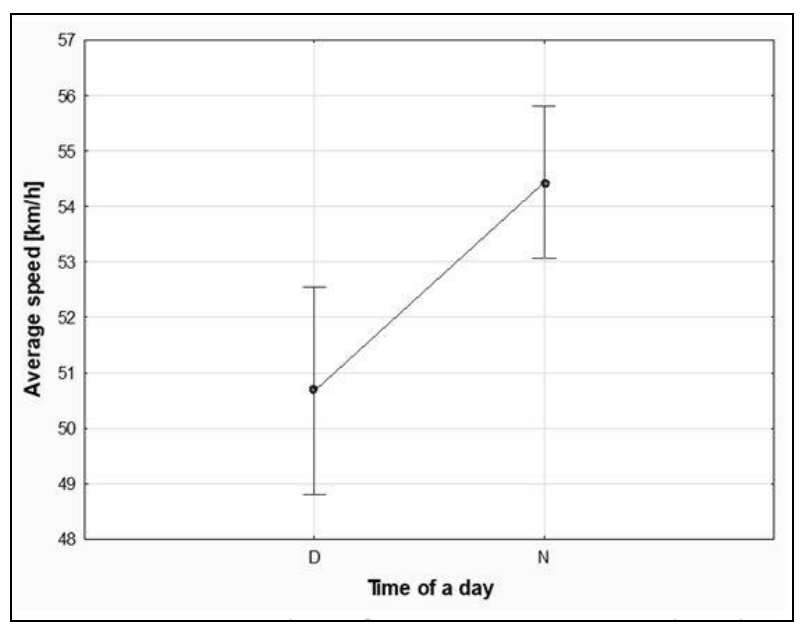

Fig. 7. Scatterplot of average V_0 speeds related to the time of a day for $1 \times 2$ cross sections.

Driver's behaviour was also analysed in relation to the time of a day. Figure 6 and Figure 7 present speed values recorded in a daytime (D) and after dark (N) on dual (Figures 6) and single carriageways (Figure 7). The figures reveal that drivers after dark drive faster than during a daytime. Difference between average speed values recorded on dual carriageways $(1,3 \mathrm{~km} / \mathrm{h})$ is smaller than difference recorded on single carriageways $(3,7 \mathrm{~km} / \mathrm{h})$. In case of dual carriageway the difference is not significant $(\mathrm{p}=, 31005)$ opposite to single carriageways where the difference is highly significant $(\mathrm{p}=, 00061)$.

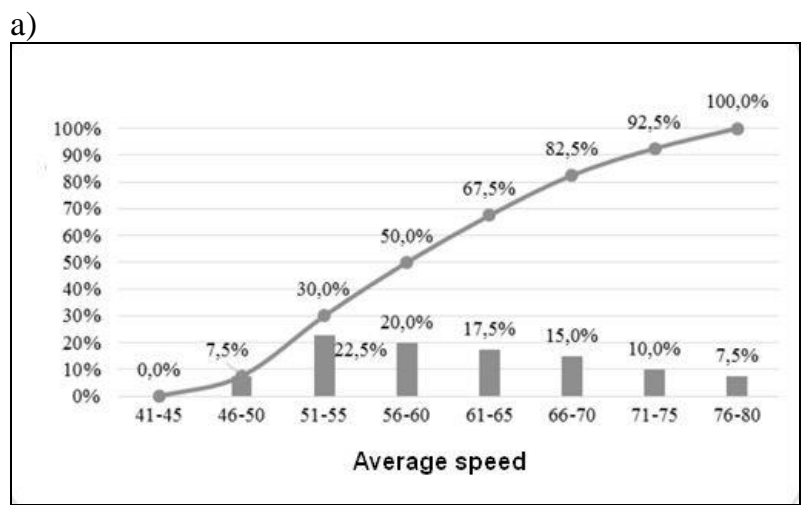




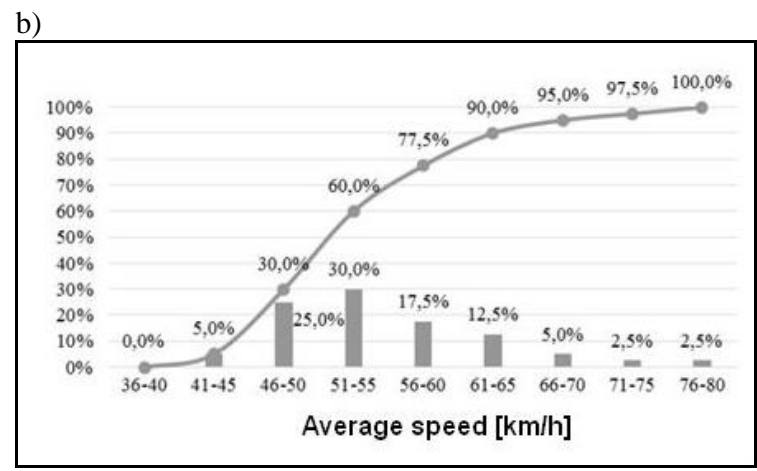

Fig. 8. A sample of speed distribution for MB pedestrian crossing a) V_100, b) V_0.

Conducted analyses in terms of driver's speed show the complexity of their behaviour which cannot be easily predicted but still must be effectively controlled in order to provide high level of pedestrians safety especially in the area of pedestrian crossings. The crucial problem arising from conducted speed surveys and analyses is driver's high speed in close vicinity of pedestrian crossings, especially if we consider potential hit energy occurring during collision vehicle-pedestrian. In case of crossings located in mid-block segments and at unsignalised intersections driver's speed while approaching the critical point remain practically at the same level as it is $50 \mathrm{~m}$ or $100 \mathrm{~m}$ distance from the crossing (the differences are statistically insignificant). Drivers seem not to consider pedestrian crossing areas as places of increased risk and increased caution that would encourage them to more careful and slower driving. The only visible and essential difference is observed along approaching sections to pedestrian crossings located at roundabouts. In such situations individuals travel with significantly reduced speed at the distance of $50 \mathrm{~m}$ from the crossing and further reduce significantly their speed to the level little over $40 \mathrm{~km} / \mathrm{h}$ - the lowest from among investigated but still bringing high risk for pedestrians assuming potential collision.

The study also revealed another disturbing fact which is drover's speed behaviour recorded after dark conditions when the presence of pedestrian is considerably lower comparing to the daytime conditions. However those circumstances don't prevent drivers from faster travelling. This is especially evident on dual carriageways where average speed increased significantly in comparison to daytime speed. In case of single carriageway the speed has also increased but to a lesser extent and the increase was not significant but still the fact remains worrying. The results of the present study also show lack of consistency in driver's speed not only at a certain distance from the pedestrian crossing but also at the crossing location (Figure 8). Based on the abovementioned there must be underline one general conclusion. A number of advanced safety measures related to vehicles, infrastructure and its environment is being implemented to reduce the number and severity of accidents with pedestrians but the number of pedestrian fatalities in recent years remain very high or is even increasing though. Due to that it seems that more attempts should be given to finding and implementing more effective speed management solutions to force drivers to slower driving in the area of pedestrian crossings - places where vulnerable road users become exposed to high risk.

The research was supported by the Project No S/WBiIS/1/15 and it was financially supported by Ministry of Science and Higher Education, Poland.

\section{References}

[1] Jamroz i in. Ochrona pieszych. Podręcznik dla organizatorów ruchu pieszego. KRBRD (2014)

[2] Hamed M.M. Analysis of pedestrians' behavior at pedestrian crossings. Safety Science, Volume 38, Issue 1, June 2001, Pages 63-82 (2001)

[3] Basile O., Persia L., Usami D.S. A methodology to assess pedestrian crossing safety. Eur. Transp. Res. Rev. 2: 129-137 (2010)

[4] Asadi-Shekari Z., Moeinaddini M., Zaly Shah M. Pedestrian safety index for evaluating street facilities in urban areas. Safety Science 74, pp. 1-14 (2015)

[5] www.etsc.eu

[6] Lexman K.K., Rastogi R., Chandra S. Pedestrian flow characteristics in mixed traffic conditions. Journal of Urban Planning and Development, 2010, 136(1), pp. 23-33.

[7] Lam W.H.K., Lee J.Y.S., Cheung C.Y. A study of the bi-directional pedestrian flow characteristics at Hong Kong signalized crosswalks facilities, Transportation, 29, pp. 169-192 (2002)

[8] Lipovac K.,Vujanic M., Maric B. et al. Pedestrian behaviour at signalized pedestrian crossings. Journal of Transportation Engineering, 139(2), pp. 165-172 (2013)

[9] Fontain H., Gourlet Y. Fatal pedestrian accidents in France: A typological analysis, Accident Analysis \& Prevention, Volume 29, Issue 3, May 1997, Pages 303-312

[10] Zegeer C.V. How to develop a pedestrian safety action plan. Final report. Washington, D.C., Federal Highway Administration, 2009 (FHWA-SA-05-12).

[11] Pesić D., Antić B., Glavić D., Milenković M. The effects of mobile phone use on pedestrian crossing behaviour at unsignalized intersections - Models for predicting unsafe pedestrians behaviour, Safety Science, Volume 82, February 2016, Pages 1-8

[12] Jamroz K., Kaczmarek J. Jak zmniejszyć poziom ryzyka pieszych w ruchu drogowym w Polsce, Transport Miejski i Regionalny, 07-08/2006, pp. 4047

[13] Tomczuk P.: Bezpieczeństwo pieszych - pomiary luminancji na przejściu dla pieszych, Prace Naukowe Politechniki Warszawskiej, Transport, Badania Środków i Systemów Transportowych, z. 
80, str.117-135, Oficyna Wydawnicza Politechniki Warszawskiej, Warszawa (2012).

[14] Jamroz K. i inni: Metodologia systematycznych badań zachowań pieszych i relacji pieszy-kierowca wraz z przeprowadzeniem badań pilotażowych. Etap I. www.krbrd.gov.pl, 2015.

[15] Olszewski P. [et al.]: Pedestrian safety assessment with video analysis, in: Transportation Research Procedia, vol. 14, 2016, pp. 2044-2053.

[16] Rosén, E., and U. Sander. Pedestrian Fatality Risk as a Function of Car Impact Speed. Accident Analysis and Prevention, Vol. 41, pp. 536-542 (2009)

[17] Gaca s., Kiec M. Assessment of Pedestrian Risk at Crossings with Kinematic-Probabilistic Model, Transportation Research Record: Journal of the Transportation Research Board, 2015, Volume 2514, Pages: 129-137

[18] Gaca S. Badania prędkości pojazdów i jej wpływ na bezpieczeństwo ruchu drogowego, Zeszyty Naukowe Politechniki Krakowskiej, Nr 75, Kraków (2002)

[19] Ziolkowski R. Influence of traffic calming measures on drivers' behaviour, 9th International Conference: Environmental engineering, Vilnius Gediminas Technical University Press Technika (2014)

[20] U.K. Department of Transportation. Killing Speed and Saving Lives. U.K. Department of Transportation, London (1987) 